MORA, N.H.A.P. et al. Análise químico-físico e sensorial de hambúrgueres formulados com carne de ovelhas de descarte. PUBVET, Londrina, V. 8, N. 17, Ed. 266, Art. 1769, Setembro, 2014.

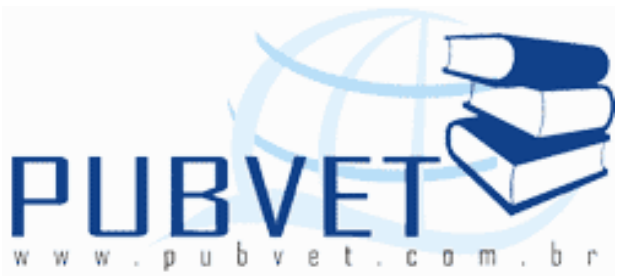

PUBVET, Publicações em Medicina Veterinária e Zootecnia.

\title{
Análise químico-físico e sensorial de hambúrgueres formulados com carne de ovelhas de descarte
}

Natália Holtz Alves Pedroso Mora ${ }^{1}$, Francisco de Assis Fonseca de Macedo², Franciane Barbiéri Dias-Senegalhe ${ }^{3}$, Ana Cláudia Radis ${ }^{3}$, Andresa Carla Feihrmann ${ }^{4}$, Ana Paula Silva Possamai ${ }^{1}$, Daniele Portela de Oliveira ${ }^{5}$, Maryane Gluck Torres ${ }^{6}$, Thiago Gomes de Macedo ${ }^{6}$

${ }^{1}$ Doutoranda em Zootecnia pela Programa de Pós-Graduação em Zootecnia UEM, Maringá-PR, natalia-mora@hotmail.com

${ }^{2}$ Professor do Curso e do Programa de Pós-Graduação em Zootecnia - UEM.

${ }^{3}$ Doutor em Zootecnia - UEM.

${ }^{4}$ Professora do Curso de Engenharia de Alimentos - UEM.

${ }^{5}$ Doutoranda do Programa de Pós-Graduação em Zootecnia - UNESPJaboticabal.

${ }^{6}$ Graduação em Zootecnia - UEM.

\section{Resumo}

Foram utilizadas oito ovelhas em final de vida reprodutiva alimentadas ad libitum durante 60 dias com ração completa misturada e peletizada. Após o abate, as paletas foram extraídas, embaladas a vácuo e armazenadas em freezer a $-18^{\circ} \mathrm{C}$ sendo desossadas para a produção de hambúrguer com diferentes proporções de carne ovina e toucinho suíno. Os hambúrgueres foram avaliados por meio de análises químicas e sensoriais para verificar a aceitabilidade dos consumidores. A umidade foi influenciada pela proporção da 
MORA, N.H.A.P. et al. Análise químico-físico e sensorial de hambúrgueres formulados com carne de ovelhas de descarte. PUBVET, Londrina, V. 8, N. 17, Ed. 266, Art. 1769, Setembro, 2014.

carne das ovelhas nos hambúrgueres, sendo menor para hambúrgueres com $85 \%$ de carne ovina. A concentração de matéria mineral, lipídios totais e perdas por cocção não diferiram $(P>0,05)$ entre os tratamentos. A proteína bruta dos hambúrgueres diminuiu com a inclusão de 30\% de toucinho suíno, comparada ao outros tratamentos. Os consumidores mostraram preferência pelos hambúrgueres formulados com $85 \%$ de inclusão de carne ovina e $15 \%$ de toucinho suíno $(P<0,05)$. Os hambúrgueres foram aceitos no teste de atitude de compra revelando um mercado positivo para este tipo de produto, se tornando uma nova estratégia para produtores, pois possui uma produção viável e uma ótima fonte proteica.

Palavras-chave: aceitação global, consumidor, ovinos, qualidade

\title{
Physico-chemical and sensory analysis made hamburgers with meat culling ewes
}

\begin{abstract}
Eight sheep were used at the end of reproductive life fed ad libitum for 60 days with mixed and pelleted complete feed. After slaughter, the shoulders were extracted, vacuum packed and stored at $-18^{\circ} \mathrm{C}$ being boneless to produce burger with different proportions of sheep meat and pork backfat. The burgers were evaluated by means of chemical and sensory analyzes to verify the acceptability of consumers. Moisture was influenced by the proportion of sheep meat in burgers, with being lower for $85 \%$ of sheep meat. The concentration of ash, total lipids and cooking losses did not differ $(P>0.05)$ between treatments. The burgers of crude protein decreased with the addition of $30 \%$ pork backfat, compared to the other treatments. Consumers showed preference for burgers formulated with $85 \%$ inclusion of sheep meat and $15 \%$ pork backfat $(P<0.05)$. The burgers were accepted into the attitude towards buying revealing a positive test for this type of product market, becoming a new strategy for producers because it has a viable production and a great protein source.
\end{abstract}

Keywords: consumer, global acceptance, sheep, quality 
MORA, N.H.A.P. et al. Análise químico-físico e sensorial de hambúrgueres formulados com carne de ovelhas de descarte. PUBVET, Londrina, V. 8, N. 17, Ed. 266, Art. 1769, Setembro, 2014.

\section{Introdução}

A ovinocultura brasileira segue aumentando a eficiência na produção de carne com participação significativa no agronegócio nos últimos anos. No rebanho geral, ovelhas com idade avançada e com problemas de reprodução diminuem a eficiência reprodutiva, recomendando-se o seu descarte (Radis, 2013). A carne de animais ovinos adultos possui características sensoriais indesejadas principalmente pelo odor e sabor forte, sendo rejeitada pela maioria dos consumidores. Devido aos fatores mencionados, carnes de ovelha de descarte alcançam baixo preço de comercialização, o que gera prejuízo aos produtores.

Segundo Rocha et al. (2007), no Brasil, são desenvolvidos subprodutos como linguiças frescais, charque, presunto, apresuntado, hambúrguer e salame, em formulações com carne ovina e suína e/ou bovina, com boa aceitação junto aos consumidores.

É de grande necessidade a valorização da carcaça de ovelhas de descarte, que pode ser feita com a inclusão de diferentes ingredientes em seu processamento para melhorar as características sensoriais, viabilizando o uso de novas tecnologias, dentre eles o hambúrguer e assim, ser uma alternativa para produtores melhorarem a renda de suas propriedades.

Este produto, elaborado adequadamente, pode ser uma opção fácil e rápida de preparo, saudável e de alto valor proteico. Por esses motivos, se tornou um alimento popular mundialmente, pois é adequado ao modo de vida que vem se instalando nos centros urbanos (Arisseto et al., 2005).

O objetivo deste trabalho foi avaliar a qualidade nutricional e sensorial de hambúrgueres com diferentes inclusões de toucinho suíno na carne de ovelhas de descarte.

\section{Material e Métodos}

Foram utilizadas oito ovelhas deslanadas, em final de vida reprodutiva alimentadas ad libitum, durante 60 dias com ração completa misturada e peletizada (Tabela 1). Para os abates, as ovelhas ficaram 18 horas sob jejum 
MORA, N.H.A.P. et al. Análise químico-físico e sensorial de hambúrgueres formulados com carne de ovelhas de descarte. PUBVET, Londrina, V. 8, N. 17, Ed. 266, Art. 1769, Setembro, 2014.

de sólidos, somente com disponibilidade de água. No momento do abate foram pesadas e imediatamente insensibilizadas por meio de descarga elétrica de 220 volts por 8 segundos e a sangria, pela secção das veias jugulares e as artérias carótidas. Terminada a evisceração, as carcaças foram transferidas para uma câmera frigorífica a $4^{\circ} \mathrm{C}$ por 24 horas, onde permaneceram penduradas pelos tendões em ganchos apropriados, mantendo as articulações tarso metatarsianas distanciadas em $17 \mathrm{~cm}$.

Tabela 1. Composição em $\mathrm{g} / \mathrm{kg}$ na matéria seca dos ingredientes fornecidos na dieta experimental.

\begin{tabular}{lc}
\hline Item & $\mathrm{g} / \mathrm{kg}$ \\
\hline Casca de soja & 503,2 \\
Feno coastcross & 208,0 \\
Milho moído & 245,1 \\
Farelo de soja & 43,7 \\
Total & 1000,0 \\
\hline
\end{tabular}

Em seguida as carcaças frias foram separadas longitudinalmente, sendo a metade esquerda seccionada em sete regiões anatômicas: pescoço, paleta, costelas descobertas, costelas, baixos, lombos e perna. As paletas foram embaladas a vácuo e armazenadas em freezer a $-18^{\circ} \mathrm{C}$, sendo posteriormente desossadas e moídas em moedor elétrico com disco de oito $\mathrm{mm}$.

Os hambúrgueres foram processados com diferentes proporções de carne ovina e toucinho suíno (Tabela 2). Para o tempero em todos os tratamentos, foram adicionados $68 \mathrm{~g}$ de condimento comercial $\left(\right.$ MAGGI ${ }^{\circledR}$ Creme de Cebola Nestlé) para cada $0,500 \mathrm{~kg}$ de carne. A mistura foi realizada manualmente, adicionando-se o condimento gradativamente, até obter-se massa homogênea. A moldagem foi realizada em hamburgueira doméstica manual de $10 \mathrm{~cm}$ de diâmetro, obtendo-se hambúrgueres com peso líquido de $100 \mathrm{~g}$ cada. Os 
MORA, N.H.A.P. et al. Análise químico-físico e sensorial de hambúrgueres formulados com carne de ovelhas de descarte. PUBVET, Londrina, V. 8, N. 17, Ed. 266, Art. 1769, Setembro, 2014.

hambúrgueres foram identificados, embalados individualmente e armazenados em freezer sob a temperatura de $-18^{\circ} \mathrm{C}$, para posteriores análises.

Tabela 2. Hambúrgueres elaborados de acordo com três processamentos.

\begin{tabular}{ccc}
\hline Grupo 1 & Grupo 2 & Grupo 3 \\
\hline $100 \%$ de carne & $85 \%$ de carne ovelha + & $70 \%$ de carne ovelha + \\
ovelha & $15 \%$ toucinho suíno & $30 \%$ toucinho suíno \\
\hline
\end{tabular}

Foram realizadas análises químicas dos hambúrgueres crus, sendo determinadas umidade, matéria mineral, e proteína bruta conforme AOAC (2000), e para lipídios totais, a extração foi feita utilizando-se a técnica a frio descrita por Folch et al. (1957), com solução de clorofórmio/metanol (2:1 v/v).

Para a realização das perdas de água por cocção, os hambúrgueres foram descongelados por 12 horas a $4^{\circ} \mathrm{C}$ e assados em "grill" elétrico, préaquecido à temperatura de $170^{\circ} \mathrm{C}$. Amostras dos hambúrgueres crus foram pesadas, embaladas em papel alumínio e colocadas no "grill", onde permaneceram até a temperatura interna do centro da amostra atingir $70^{\circ} \mathrm{C}$, monitorada com termômetro digital (Delta OHM, modelo HD9218, Itália), e quando esfriaram, foram pesados novamente para cálculo de porcentagem de perdas por cocção.

Todas as análises foram realizadas em triplicatas, no intuito de aumentar a confiabilidade dos resultados.

Para a análise sensorial dos hambúrgueres, foi aplicado teste de preferência para verificação da amostra que o provador mais gostou e menos gostou. Além disso, foi aplicado o teste de intenção de compra do produto através de pergunta fechada, com as respostas "sim" e "não". As análises sensoriais foram realizadas em uma sessão na Universidade Estadual de Maringá com 80 consumidores, sendo selecionados por sexo e idade para ser representativo da população de Maringá. 
MORA, N.H.A.P. et al. Análise químico-físico e sensorial de hambúrgueres formulados com carne de ovelhas de descarte. PUBVET, Londrina, V. 8, N. 17, Ed. 266, Art. 1769, Setembro, 2014.

O hambúrguer foi servido após ser preparado em "grill" seguindo a metodologia das perdas de água por cocção, em cubos de aproximadamente 2 $\mathrm{cm}$, embalados em papel alumínio e codificados com três dígitos para serem completados nos testes.

Para realização das análises estatísticas utilizou-se o software $R$ (2009), constatou-se normalidade de todas as variáveis pelo teste de Shapiro-Wilk e procedeu-se a analise de variância e teste de Tukey para verificar a diferença significativa entre os tratamentos, considerando o nível de significância de 5\%.

Para a analise sensorial adotou-se a metodologia de modelos lineares generalizados considerando uma distribuição binomial com função de ligação da família logit para analisar as observações.

\section{Resultados e Discussão}

$\mathrm{Na}$ Tabela 3 foram observadas diferenças $(P<0,05)$ para alguns parâmetros na composição química dos hambúrgueres com diferentes proporções da carne de ovelha de descarte.

Tabela 3. Médias e erros-padrão da composição química dos hambúrgueres de diferentes proporções de carne de ovelhas de descarte

\begin{tabular}{cccc}
\hline & \multicolumn{3}{c}{ Diferentes inclusões da carne ovina:toucinho suíno } \\
\cline { 2 - 4 } Item (\%) & $100: 0$ & $85: 15$ & $70: 30$ \\
\hline Umidade & $58,68 \pm 0,51 \mathrm{a}$ & $58,09 \pm 0,51 \mathrm{~b}$ & $58,35 \pm 0,51 \mathrm{a}$ \\
Matéria Mineral & $2,42 \pm 0,03 \mathrm{a}$ & $2,37 \pm 0,03 \mathrm{a}$ & $2,45 \pm 0,03 \mathrm{a}$ \\
Proteína Bruta & $21,27 \pm 0,30 \mathrm{a}$ & $20,35 \pm 0,30 \mathrm{a}$ & $16,86 \pm 0,30 \mathrm{~b}$ \\
Lipídios Totais & $15,12 \pm 0,62 \mathrm{a}$ & $12,74 \pm 0,62 \mathrm{a}$ & $12,33 \pm 0,62 \mathrm{a}$ \\
PPC $^{1}$ & $2,30 \pm 0,33 \mathrm{a}$ & $1,59 \pm 0,33 \mathrm{a}$ & $2,84 \pm 0,33 \mathrm{a}$
\end{tabular}

Médias seguidas de letras iguais indicam que não houve diferença pelo teste Tukey $(P<0,05)$; ${ }^{1} \mathrm{PPC}=$ Perdas por cocção.

A umidade foi influenciada $(P<0,05)$ pela proporção da carne das ovelhas de descarte nos hambúrgueres, sendo hambúrgueres formulados com $85 \%$ de 
MORA, N.H.A.P. et al. Análise químico-físico e sensorial de hambúrgueres formulados com carne de ovelhas de descarte. PUBVET, Londrina, V. 8, N. 17, Ed. 266, Art. 1769, Setembro, 2014.

carne ovina e $15 \%$ de toucinho suíno com menores valores. Caye et al. (2009a) utilizando carnes de ovelha para fabricação de hambúrgueres encontrou valor da umidade maior $(72,4 \%)$ que estes resultados. Em animais a proporção de água:matéria mineral e proteínas diminuem lentamente com a idade e ocorre um incremento na proporção de gordura no corpo (Santos, 2008).

A concentração de matéria mineral não diferiu $(P>0,05)$ nos hambúrguer de diferentes proporções de carne de ovelhas de descarte. Entretanto as médias dos tratamentos encontram-se de acordo com a literatura utilizando carne ovina para fabricação de hambúrgueres (Caye et al., 2009a; Santos Junior et al., 2009)

A proteína bruta dos hambúrgueres diminuiu com a inclusão de $30 \%$ de toucinho suíno, comparada ao outros tratamentos. Destaca-se o valor da proteína bruta de hambúrgueres com $100 \%$ de carne de ovelhas de descarte, revelando-se um produto com alta qualidade de proteína animal para os consumidores, diferindo dos hambúrgueres convencionais no mercado.

Não houve efeito $(P>0,05)$ para lipídios totais, que variam de $12,33 \%$ a $15,12 \%$. O teor de gordura é uma característica que apresenta importante papel no sabor, na suculência e na maciez da carne e seus co-produtos, mas neste experimento, não diferiram entre os tratamentos. Entretanto, os hambúrgueres de todos os tratamentos estão de acordo com o Regulamento Técnico de Identidade e Qualidade do Hambúrguer (Brasil, 2000), que estabelece um teor mínimo de $15 \%$ para proteínas e máximo de $23 \%$ para gordura.

Os resultados não diferiam $(\mathrm{P}<0,05)$ para as análises de perdas de água por cocção. Deve-se considerar que a metodologia utilizada neste experimento, para o cozimento do hambúrguer foi feito em "grill", com as amostras acondicionadas em papel alumínio, diminuindo assim, as perdas de água e cocção. Fator importante por proporcionar maior suculência aos hambúrgueres preparados. Segundo Silva (2008), a perda de peso na cocção varia segundo o genótipo do animal, condições de manejo do abate e a 
MORA, N.H.A.P. et al. Análise químico-físico e sensorial de hambúrgueres formulados com carne de ovelhas de descarte. PUBVET, Londrina, V. 8, N. 17, Ed. 266, Art. 1769, Setembro, 2014.

metodologia no preparo das amostras, tais como a remoção ou padronização da capa de gordura subcutânea e tipo de equipamento, fatores que podem levar a variação da temperatura no processo de cocção.

A Tabela 4 apresenta as médias e erros-padrão para os testes de preferência na análise sensorial dos hambúrgueres com diferentes proporções da carne ovina.

Tabela 4. Médias e erros-padrão para preferência de hambúrgueres de diferentes proporções de carne de ovelhas de descarte

\section{Diferentes inclusões da carne ovina:toucinho suíno}

\begin{tabular}{lccc}
\hline Item & $100: 0$ & $85: 15$ & $70: 30$ \\
Preferência & $29 \pm 9 b$ & $43 \pm 9 a$ & $29 \pm 9 b$ \\
\hline
\end{tabular}

Os consumidores mostraram preferência pelos hambúrgueres formulados com $85 \%$ de inclusão de carne de ovelha de descarte e $15 \%$ de toucinho suíno $(P<0,05)$, o que pode estar associado ao sabor menos intenso da carne ovina e sua gordura, que possui compostos aromáticos específicos.

Para a intenção de compra dos hambúrgueres (Tabela 5), não houve diferença $(P>0,05)$ entre sexo, mostrando que acima de $90 \%$ dos provadores comprariam o produto, concordando com Caye et al. (2009b), que obteve $95,3 \%$ de aceitação em hambúrgueres utilizando carne de ovelhas de descarte.

Tabela 5. Médias e erros-padrão para atitude de compra dos hambúrgueres

\begin{tabular}{lcc}
\hline Item & 1 & 2 \\
\hline Sexo & $93 \pm 6 \mathrm{a}$ & $91 \pm 7 \mathrm{a}$ \\
Idade & $88 \pm 6 \mathrm{~b}$ & $95 \pm 7 \mathrm{a}$
\end{tabular}

Médias seguidas de letras iguais indicam que não houve diferença pelo teste Tukey $(P<0,05)$

sexo: $1=$ homem; $2=$ mulher; idade: $1=20$ a 40 anos; $2=40$ a 60 anos. 
MORA, N.H.A.P. et al. Análise químico-físico e sensorial de hambúrgueres formulados com carne de ovelhas de descarte. PUBVET, Londrina, V. 8, N. 17, Ed. 266, Art. 1769, Setembro, 2014.

A maior atitude de compra do produto foi por pessoas com idade acima de 40 anos. Entretanto, deve se chamar atenção da importância desse resultado, uma vez que a atitude de compra foi acima de $88 \%$ para pessoas de 20 a 40 anos, onde normalmente, há maior consumo de hambúrguer. Seria necessário investir em propagandas comerciais para o conhecimento e estimulação de venda no mercado, principalmente para um nicho consumidor específico de carne ovina, já que os resultados de aceitação de venda foram positivos.

\section{Conclusões}

Os hambúrgueres foram aceitos no teste de atitude de compra, tendo preferência para hambúrgueres com $85 \%$ de carne de ovelha de descarte e $15 \%$ de toucinho suíno, revelando um mercado positivo para este tipo de produto, se tornando uma nova estratégia para produtores e uma inovação na mesa dos consumidores. Hambúrgueres de carne de ovelha de descarte são uma ótima fonte proteica, se enquadram dentro das normas de comercialização e possuem produção viável.

\section{Literatura citada}

ASSOCIATION OF OFFICIAL ANALYTICAL CHEMISTIS - AOAC. Official methods of analysis. 13.ed. Arlington: AOAC International, 2000. 989p.

ARISSETO, A.P.; POLLONIO, M.A.R. Avaliação da estabilidade oxidativa do hambúrguer tipo calabresa, formulado com reduzidos teores de nitrito diferentes percentagens de gordura, durante armazenamento congelado. Higiene Alimentar, v.19, p.72-80, 2005.

BRASIL. Ministério da Saúde. Agência Nacional de Vigilância Sanitária. Instrução Normativa no 20/2000. Regulamento Técnico de Identidade e Qualidade do Hambúrguer. Brasília, 2000. Disponível em: <http://www.agricultura.gov.br>. Acesso em: 20/10/2013.

CAYE, L.; FRANÇOIS, P.; SANTOS, M. V. Avaliação físico-química de hambúrguer elaborado com carne ovina. In: III Seminário: Sistemas de Produção Agropecuária - Ciência e Tecnologia de Alimentos - UTFPR. Anais... Dois Vizinhos, 2009a.

CAYE, L.; FRANÇOIS, P.; SANTOS, M. V. Hambúrguer de carne ovina: aceitabilidade do consumidor. In: III Seminário: Sistemas de Produção Agropecuária - Ciência e Tecnologia de Alimentos - UTFPR. Anais... Dois Vizinhos, 2009b.

FOLCH, J.; LESS, M.; SLOANE, S.G.H. A simple method for the isolation and purification of total lipids from animal tissues. The Journal of Biological Chemistry, v.226, n.1, p.497509, 1957. 
R Development Core Team (2009). R: A language and environment for statistical computing. R Foundation for Statistical Computing, Vienna, Austria. ISBN3-900051-07-0, URL http://www.R-project.org

RADIS, A.C. Revalorização, característica de carcaça e da carne de ovelhas de descarte alimentadas com dietas contendo diferentes proporções de grãos de linhaça. 2013. 78f. Tese (Doutorado em Zootecnia), - Universidade Estadual de Maringá, Maringá - PR.

ROCHA, H.C.; DICKEL, E.L.; MESSINA, S. A. Produção de cordeiro de corte em sistema de consorciação. Passo Fundo: Universidade de Passo Fundo: Universidade de Passo Fundo, UPF, 2007. 64p.

SANTOS JR, L.C.O., RIZZATTI, R.; BRUNGERA, A. Desenvolvimento de hambúrguer de carne ovinos de descarte enriquecidos com farinha de aveia. Ciência Animal Brasileira, v. 10, n.4, p.1128-1134, 2009.

SANTOS, C.L.; PEREZ, J, R.O.; CRUZ, C. A. C. et al. Análise centesimal dos cortes da carcaça de cordeiros Santa Inês e Bergamácia. Ciência e tecnologia de alimentos. v. 28, p. 51$59,2008$.

SILVA, N. V. Radares técnicos - qualidade da carne ovina e fatores de influência. Farm Point. Piracicaba. 2008. Disponível em: <http://www.farmpoint.com.br>. Acesso em: 20/10/2013. 